\title{
Chronic glomerulonephritis and exposure to solvents: a case-referent study
}

\author{
Antonio Porro, Carlo Lomonte, Pasquale Coratelli, Giuseppe Passavanti, Giovanni Maria Ferri, \\ Giorgio Assennato
}

\begin{abstract}
To evaluate the risk of chronic glomerulonephritis in subjects exposed to solvent vapours, a case-referent study was carried out. The case group, including 60 patients $(44$ men and 16 women) with non-systemic chronic glomerulonephritis, established by biopsy, was compared with 120 control subjects (60 patients with traumatic fractures and 60 patients affected by nephrolithiasis) matched by sex and age. Information on occupational and non-occupational exposure to solvent was obtained by questionnaire. The exposure scores drawn from questionnaires were significantly higher in the case group than in the referent groups for both total and occupational solvent exposure. No significant differences in non-occupational exposure were found. The odds ratio of chronic glomerulonephritis for occupationally exposed (score $>0$ ) was 3.9 (95\% confidence interval (95\% CI) $1 \cdot 64-8 \cdot 33)$. When IgA nephropathy patients $(n=27)$ were separately evaluated, an increased risk was found for both total and occupational exposure. Using a logistic regression model, a dose-response effect for occupational exposure was seen. The results support the hypothesis that chronic glomerulonephritis may be related to environmental factors such as exposure to hydrocarbons.
\end{abstract}

During the past several years exposure to solvent vapours has been related to nephrotoxic effects. Exposure to solvents has been associated with acute tubular necrosis, interstitial disease, and several

Institute of Occupational Health, University of Bari, Bari, Italy

A Porro, G M Ferri, G Assennato

F Miulli Hospital, Department of Nephrology and Dialysis, Acquaviva delle Fonti, Italy

C Lomonte

Institute of Nephrology, University of Bari, Bari, Italy

P Coratelli, G Passavanti histological types of glomerulonephritis. ${ }^{1-5}$ Casecontrol investigations carried out in Sweden and Great Britain found a significant excess in solvent exposure for cases of glomerulonephritis and are consistent in suggesting that exposure to hydrocarbons may lead to the development of glomerular diseases. ${ }^{6-8}$ The risk of end stage renal disease (ESRD) was significantly related to occupational exposure to solvents in another case-control study conducted using the Michigan kidney registry data. ${ }^{9}$ In patients with non-systemic proliferative glomerulonephritis a clinical improvement has been described after avoidance of exposure to solvents. ${ }^{10}$ In Italy more than 23000 patients suffer from ESRD and require dialysis; moreover, each year nearly 90 new cases per million residents are reported. ${ }^{11}$ Many cases are nonsystemic glomerulonephritis. ${ }^{12}$ In, the present investigation the question of whether exposure to organic solvents can be regarded as a risk factor for nonsystemic chronic glomerulonephritis has been considered.

Patients and methods

The group of cases was identified from clinical records of the nephrology department at the University of Bari. Subjects eligible for the study were patients affected by chronic non-systemic glomerulonephritis as indicated by biopsy examination, aged 14 years or older, and living in the province of Bari (southern Italy) at the time of biopsy examination (performed in the nephrology department between 1 January 1983 and 31 December 1987). Subjects with clinical or serological evidence of systemic disease (diabetes, systemic lupus erythematosus, streptococcal infection, mixed cryoglobulinaemia, amyloidosis, vasculitis) were excluded.

Among the 188 patients with glomerulonephritis biopsied in the nephrology department over the five year period, 71 were eligible and were asked for interview. Ten subjects did not answer or declined to participate (six men and four women; average age: $25 \cdot 10$ (standard deviation (SD)) $7 \cdot 61$; histological classification: five IgA nephropathy, two 
endocapillary proliferative glomerulonephritis, two focal segmental glomerulosclerosis, one minimal changes disease); a 17 year old male patient died in 1986 in an accident.

Table 1 shows the distribution of the 60 cases by sex and histological diagnosis.

Two control groups, both including 60 subjects matched (matching ratio $1: 2$ ) to cases by sex and age ( \pm 5 years), were selected:

(1) the first was selected from outpatients with traumatic fractures at the orthopaedic department of the University of Bari; subjects who reported signs or symptoms of nephropathy were excluded; (2) the second consisted of outpatients affected by nephrolithiasis (with no evidence of glomerular disease) selected in the nephrology department.

Subjects living out of the province of Bari and aged 13 or younger were excluded from control groups.

Information on exposure to solvents was collected by an interviewer using a structured questionnaire. Neither cases nor controls were aware of the hypotheses of the study and had not been previously questioned about exposure to solvent before the interview. Cases were interviewed between 12 May 1987 and 4 April 1989; referents were interviewed between 1 June 1987 and 18 July 1990. The interviews of cases of glomerulonephritis and patients with nephrolithiasis were performed in the nephrology department, those of outpatients with traumatic fractures in the orthopaedic department.

The questionnaire was designed to assess duration and intensity of contact with solvents in occupational and non-occupational (spare time, use of household products) activities. Exposure was truncated at the time of diagnosis of glomerulonephritis for cases and their matched controls.

The completed interviews were reviewed by an industrial hygienist blind to whether the patients were cases or controls. The solvent exposure was estimated according to Ravnskov et $a l^{6}$ and to Bell et $a l .^{8}$ For each activity with exposure to solvents the number of hours of exposure each week was multiplied by the number of years (or by the fraction of year) in which the activity had been practised. The duration of exposure was multiplied by a factor of intensity of solvent exposure. The products were summed over all jobs for each subject to obtain a cumulative exposure score (divided into occupational and non-occupational).

The intensity of solvent exposure was graded as follows.

(a) Intensity factor 2-production of paint and glue, occupational painting indoors, spray painting without protection devices, polyester resin application with heavy contact with styrene, tank cleaning without protection devices, carpet cleaning.

(b) Intensity factor 1-non-occupational painting indoors, spray painting with protection devices, industrial degreasing of metals, printing work (rotogravure), occupational gluing (including vamps gluing), dry cleaning, anaesthetic work, occupational use of hair sprays, use of pesticides, polyester resin application with low exposure to styrene.

(c) Intensity factor 0.5 -outdoor painting, motor repairing, hobby gluing, drawing with felt tipped pens, exposure to exhaust fumes outdoors, handling of petrol fuels, degreasing of metals (excluding industrial degreasing).

Wilcoxon's signed rank sum test for paired observations was used to compare the distribution of the scores between the groups. To estimate an epidemiological association, odds ratios (ORs) and $95 \%$ confidence intervals ( $95 \%$ CIs) were calculated according to the matching procedures. ${ }^{13}$ Conditional logistic regression models were developed and tested to consider simultaneously the effect of the occupational and the non-occupational exposure and to estimate a dose-response relation. ${ }^{14}$ For analysis by level of exposure, "dummy variables" were created categorising the occupational and the nonoccupational exposure scores: both the scores were divided into higher exposure (exposed at or above median value of exposed subjects), lower exposure (exposed below the median value), and no exposure. Odds Ratios were calculated for the higher and lower exposure groups versus the no exposure group; the Mantel extension test ${ }^{15}$ was used to assess a monotonic trend in ORs. Logistic regresson models including the residence in the metropolitan area of Bari as confounding factor were also tested. A dichotomous variable indicated the residence (metropolitan area of Bari or elsewhere). Statistical analyses were performed using SAS and Epilog Plus.

\section{Results}

The average age was 27.5 (SD 11.7) years in the group of patients with glomerulonephritis and 28.0 (SD 11.9) years in the referents. Twenty four cases lived in the metropolitan area of Bari when renal biopsy was performed and 72 referents were residents of Bari at the time of biopsy of their matched case.

Table 1 Histological classification of 60 cases of chronic non-systemic glomerulonephritis

\begin{tabular}{lccc}
\hline Diagnosis & $\begin{array}{c}\text { Men } \\
(\text { No) }\end{array}$ & $\begin{array}{l}\text { Women } \\
(\text { No) }\end{array}$ & Total \\
\hline IgA nephropathy & 21 & 6 & 27 \\
Focal segmental glomerulosclerosis & 6 & 1 & 7 \\
$\begin{array}{l}\text { Membranous glomerulonephritis } \\
\text { Endocapillary proliferative }\end{array}$ & 4 & 2 & 6 \\
glomerulonephritis & 2 & 4 & 6 \\
$\begin{array}{l}\text { Mesangial proliferative glomerulonephritis } \\
\text { Minimal changes disease }\end{array}$ & 4 & 1 & 5 \\
Membranoproliferative glomerulonephritis & 2 & 2 & 4 \\
Crescentic glomerulonephritis & 1 & - & 4 \\
Total & 44 & 16 & 60 \\
\hline
\end{tabular}


Table 2 Medians, 75th percentiles, and ranges of scores in patients with glomerulonephritis and in two control groups

\begin{tabular}{|c|c|c|c|c|c|c|c|c|c|c|}
\hline & \multirow[b]{2}{*}{ No } & \multicolumn{3}{|c|}{ Total score } & \multicolumn{3}{|c|}{ Occupational score } & \multicolumn{3}{|c|}{ Non-occupational score } \\
\hline & & Median & $\begin{array}{l}75 \text { th } \\
\text { percentile }\end{array}$ & Range & Median & $\begin{array}{l}\text { 75th } \\
\text { percentile }\end{array}$ & Range & Median & $\begin{array}{l}\text { 75th } \\
\text { percentile }\end{array}$ & Range \\
\hline $\begin{array}{l}\text { Glomerulonephritis } \\
\text { Nephrolithiasis } \\
\text { Trauma }\end{array}$ & $\begin{array}{l}60 \\
60 \\
60\end{array}$ & $\begin{array}{l}1 \cdot 91 \star \\
0 \\
0 \cdot 07\end{array}$ & $\begin{array}{r}123.92 \\
1.67 \\
9.58\end{array}$ & $\begin{array}{l}0-2573.33 \\
0-467 \cdot 69 \\
0-669 \cdot 70\end{array}$ & $\begin{array}{l}0 \dagger \\
0 \\
0\end{array}$ & $\begin{array}{c}123 \cdot 92 \\
0 \\
2 \cdot 64\end{array}$ & $\begin{array}{l}0-2573 \cdot 33 \\
0-467 \cdot 69 \\
0-669 \cdot 70\end{array}$ & $\begin{array}{l}0 \\
0 \\
0\end{array}$ & $\begin{array}{l}0 \\
0 \\
0.98\end{array}$ & $\begin{array}{l}0-144 \cdot 30 \\
0-39 \cdot 46 \\
0-96 \cdot 00\end{array}$ \\
\hline
\end{tabular}

^The total score in the glomerulonephritis group was significantly larger (Wilcoxon's signed rank sum test) than that in the nephrolithiasis group ( $<<0.002)$ and than that in trauma group $(\mathrm{p}<0.02)$.

†Te occupational score in the glomerulonephritis group was significantly larger (Wilcoxon's signed rank sum test) than that in the nephrolithiasis group $(\mathrm{p}<0.001)$ and than that in the trauma group $(\mathrm{p}<0.02)$.

Table 3 Medians, 75th percentiles, and ranges of scores in patients with Ig $A$ nephropathy and in two control groups

\begin{tabular}{|c|c|c|c|c|c|c|c|c|c|c|}
\hline & \multirow[b]{2}{*}{ No } & \multicolumn{3}{|c|}{ Total score } & \multicolumn{3}{|c|}{ Occupational score } & \multicolumn{3}{|c|}{ Non-occupational score } \\
\hline & & Median & $\begin{array}{l}\text { 75th } \\
\text { percentile }\end{array}$ & Range & Median & $\begin{array}{l}\text { 75th } \\
\text { percentile }\end{array}$ & Range & Median & $\begin{array}{l}\text { 75th } \\
\text { percentile }\end{array}$ & Range \\
\hline $\begin{array}{l}\text { Glomerulonephritis } \\
\text { Nephrolithiasis } \\
\text { Trauma }\end{array}$ & $\begin{array}{l}27 \\
27 \\
27\end{array}$ & $\begin{array}{l}5 \cdot 61^{\star} \\
0 \\
0\end{array}$ & $\begin{array}{l}90.00 \\
0 \\
6.00\end{array}$ & $\begin{array}{l}0-492 \cdot 00 \\
0-200 \cdot 00 \\
0-188.46\end{array}$ & $\begin{array}{l}0 \dagger \\
0 \\
0\end{array}$ & $\begin{array}{l}40 \cdot 00 \\
0 \\
0\end{array}$ & $\begin{array}{l}0-492.00 \\
0-200.00 \\
0-188.46\end{array}$ & $\begin{array}{l}0 \\
0 \\
0\end{array}$ & $\begin{array}{l}0 \cdot 30 \\
0 \\
0 \cdot 50\end{array}$ & $\begin{array}{l}0-144.30 \\
0-39.46 \\
0-11.63\end{array}$ \\
\hline
\end{tabular}

*The total score in the glomerulonephritis group was significantly larger (Wilcoxon's signed rank sum test) than that in the nephrolithiasis group $(\mathrm{p}<0.03)$ and than that in trauma group $(\mathrm{p}<0.04)$.

$\dagger$ The occupational score in the glomerulonephritis group was significantly larger (Wilcoxon's signed rank sum test) than that in the nephrolithiasis group $(p<0.02)$.

Table 2 shows the values of median, 75 th percentile, and range of the scores by group. Total and occupational exposure scores were significantly greater in the glomerulonephritis group than in the two control groups. No significant difference was found for the non-occupational exposure and between the two control groups.

When the subgroup of patients with IgA nephropathy $(n=27)$ and their matched referents were separately examined, cases appeared to be significantly more exposed than the subjects with nephrolithiasis for the total and the occupational exposure scores; only total exposure score showed a significant difference comparing the IgA nephropathy group with the patients with trauma (table 3 ).

Subjects with a score above 0 (exposed) had an OR of non-systemic glomerulonephritis for solvent exposure of 1.86 (95\% CI 0.96-3.54). A significantly increased risk was seen for occupational exposure (OR $=3.9 ; 95 \%$ CI 1.64-8.33); non-occupational exposure did not appear to affect the risk for chronic glomerulonephritis (table 4). The odds ratio values for both total and occupational exposure in patients with IgA nephropathy were significantly increased (table 5).

Table 6 presents the results of a logistic regression model in which occupational and non-occupational scores were categorised and placed as dummy variables; the risk estimates are relative to the unexposed group. Even if only higher occupational exposure showed a significantly increased adjusted $O R$ $(\mathrm{OR}=5 \cdot 4 ; 95 \%$ CI $2 \cdot 0-14 \cdot 6)$, a dose-response trend for occupational exposure appears clear $(\mathrm{p}=0.0002)$. Logistic regression models including residence in the Bari metropolitan area did not significantly affect the results of the previous model.

\section{Discussion}

The findings of this case-referent study suggest a dose-response relation between occupational

Table 4 Distribution of triads, Mantel-Haenszel relative risk estimates, and $95 \%$ CIs for total, occupational, and non-occupational exposure score and chronic glomerulonephritis $(n=60)$ - matched analysis (matching ratio $1: 2$

\begin{tabular}{|c|c|c|c|c|}
\hline & \multicolumn{3}{|c|}{ No of exposed referents } & \multirow[b]{2}{*}{ Total } \\
\hline & 0 & 1 & 2 & \\
\hline & \multicolumn{3}{|c|}{ Total exposure score } & \\
\hline $\begin{array}{l}\text { Cases not exposed } \\
(\text { score }=0)\end{array}$ & 10 & 13 & 4 & 27 \\
\hline $\begin{array}{l}\text { Cases exposed } \\
(\text { score }>0)\end{array}$ & 9 & 21 & 3 & 33 \\
\hline \multirow[t]{2}{*}{ Total } & 19 & 34 & 7 & 60 \\
\hline & \multicolumn{3}{|c|}{ Occupational exposure score } & \\
\hline $\begin{array}{l}\text { Cases not exposed } \\
(\text { score }=0)\end{array}$ & 24 & 10 & 0 & 34 \\
\hline $\begin{array}{l}\text { Cases exposed } \\
(\text { score }>0)\end{array}$ & 13 & 13 & 0 & 26 \\
\hline Total & 37 & 23 & 0 & 60 \\
\hline $\begin{array}{l}\text { Cases not exposed } \\
(\text { score }=0)\end{array}$ & $\begin{array}{c}\text { Non-o } \\
24\end{array}$ & $\begin{array}{c}\text { nale } \\
24\end{array}$ & $\begin{array}{c}\text { e score } \\
0\end{array}$ & 48 \\
\hline $\begin{array}{l}\text { Cases exposed } \\
(\text { score }>0)\end{array}$ & 4 & 7 & 1 & 12 \\
\hline Total & 28 & 31 & 1 & 60 \\
\hline
\end{tabular}

Mantel-Haenszel relative risk for total exposure score $1.86(95 \%$ CI 0.96-3.54); for occupational exposure score 3.90 (95\% CI 1.648.33); for non-occupational exposure score 0.62 (95\% CI $0.32-$ 1.30). 
Table 5 Distribution of triads, Mantel-Haenszel relative risk estimates, and 95\% CIs for total, occupational, and non-occupational exposure score and $\operatorname{Ig} A$ nephropathy $(n=27)$ - matched analysis (matching ratio 1:2)

\begin{tabular}{|c|c|c|c|c|}
\hline & \multicolumn{3}{|c|}{ No of exposed referents } & \multirow[b]{2}{*}{ Total } \\
\hline & 0 & 1 & 2 & \\
\hline \multicolumn{5}{|c|}{ Total exposure score } \\
\hline $\begin{array}{l}\text { Cases not exposed } \\
(\text { score }=0)\end{array}$ & 6 & 4 & 1 & 11 \\
\hline $\begin{array}{l}\text { Cases exposed } \\
(\text { score }>0)\end{array}$ & 6 & 9 & 1 & 16 \\
\hline Total & 12 & 13 & 2 & 27 \\
\hline $\begin{array}{l}\text { Cases not exposed } \\
(\text { score }=0)\end{array}$ & $\begin{array}{c}O c c t \\
12\end{array}$ & $\begin{array}{c}\text { al exp } \\
4\end{array}$ & $\begin{array}{c}\text { core } \\
0\end{array}$ & 16 \\
\hline $\begin{array}{l}\text { Cases exposed } \\
(\text { score }>0)\end{array}$ & 6 & 5 & 0 & 11 \\
\hline Total & 18 & 9 & 0 & 27 \\
\hline $\begin{array}{l}\text { Cases not exposed } \\
(\text { score }=0)\end{array}$ & $\begin{array}{c}\text { Non-o } \\
\quad 12\end{array}$ & $\begin{array}{r}\text { onal } \\
7\end{array}$ & $\begin{array}{l}\text { e scor } \\
0\end{array}$ & 19 \\
\hline $\begin{array}{l}\text { Cases exposed } \\
(\text { score }>0)\end{array}$ & 4 & 4 & 0 & 8 \\
\hline Total & 16 & 11 & 0 & 27 \\
\hline
\end{tabular}

Mantel-Haenszel relative risk for total exposure score 3.50 (95\% CI 1.18-12.18); for occupational exposure score $4 \cdot 25(95 \%$ CI 1.18-16.36); for non-occupational exposure score 1.71 (95\% CI $0 \cdot 57-4 \cdot 94)$.

exposure to solvents and risk of chronic non-systemic glomerulonephritis and are consistent with those of previous studies carried out in European countries and in the United States. ${ }^{6-10}$ Two case-referent studies failed to find an association between solvents and glomerulonephritis: (1) the study conducted in The Netherlands ${ }^{16}$ had a limited statistical power to detect a significantly increased risk; (2) in the study by Harrington et al $^{17}$ patients with chronic glomerulonephritis were excluded and referents were matched also by socioeconomic level so that they could be similar to the cases for occupational variables. ${ }^{18}$

The statistical analysis shows that nonoccupational exposures do not increase the risk of glomerulonephritis. The lack of an association between proliferative glomerulonephritis and nonoccupational exposure was also found in the study by Bell et al. ${ }^{8}$

No one among the 60 patients with glomerulone- phritis in this study reported acute episodes of exposure to solvent vapours. The findings seem to be in agreement with the hypothesis that the onset of glomerulonephritis could be related to non-acute exposure to solvents, even of light intensity. Among the 26 occupationally exposed cases, the job titles most represented were construction workers (six comprising bricklayers, painters, decorators), shoemakers (four), and car body shop workers (four, two showing occupational score greater than 1000 with durations of exposure of 14 and 32 years).

Only cases and referents living in the province of Bari were selected for this study. The proportion of patients with glomerulonephritis living in the Bari metropolitan area was smaller than that among referents. To eliminate possible confounding effects due to this different distribution, the residence in the area of Bari was added in the logistic models. No effect on the exposure ORs was seen, however, suggesting that this factor was not an important confounder for exposure to solvents.

Two control groups were chosen selecting patients from diseases not associated either with a reduced likelihood of employment or with the exposure variables. The degree of exposure was similar between the two control groups: this finding is in agreement with the hypothesis that nephrolithiasis and traumatic fractures are unassociated with solvent exposure.

It was impossible to blind the interviewer about the subjects' disease; nevertheless the occurrence of interviewer bias seems unlikely because she was not aware of either the aims or the design of the study.

Several mechanisms have been suggested for solvent-induced glomerular impairment: ${ }^{4}$

(a) chemical damage to either the pulmonary capillary alveolar basement membrane (ABM) or the glomerular basement membrane (GBM) inducing an antigen-antibody response; (b) indirect immunological process mediated by tubular antigens: GBM and tubular basement membrane are recognised to be antigenically similar. The origin of the antigens remains uncertain. (c) direct toxic effect on GBM; solvents may induce a proliferative reaction as a

Table 6 Adjusted logistic regression coefficients, ORs, and 95\% CIs for occupational and non-occupational categorised exposure scores

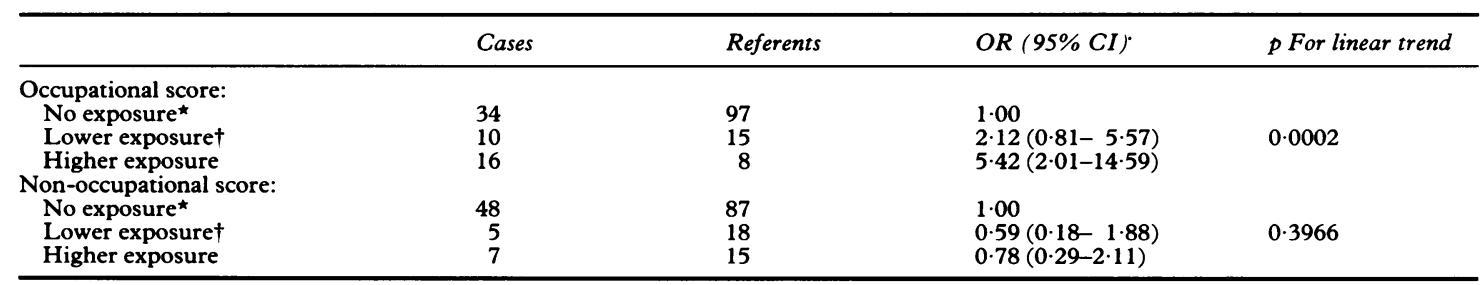

$\star$ Reference category.

†Lower and higher exposure are defined using as cut off point the median values of exposed subjects (cases and referents). The median value was $80 \cdot 12$ for the occupational score and $2 \cdot 76$ for the non-occupational score. 
direct response to chemical injury against the mesangial cells.

Given the small size of other histological subgroups, only the subgroup of IgA nephropathy $(n=27)$ was separately examined. An association between solvents and this histological type was detected. Some authors ${ }^{1920}$ have pointed out that environmental factors (like long-term solvent exposure) could alter the "mucosal immune system" and lead to the glomerulopathy with mesangial IgA deposits.

In summary, this study found an association between non-systemic glomerulonephritis and occupational exposure to solvent vapours. Because exposure to solvents is quite common whereas glomerulonephritis occurs rarely in the general population, genetic or other predisposing factors (drugs, diet, other occupational exposures like metallic fumes etc) must act in the development of solvent induced glomerulonephritis. ${ }^{4}$ A deeper knowledge about the environmental factors involved in the pathogenesis of chronic non-systemic glomerular diseases is required. For example, further investigations are suggested to identify types of hydrocarbons, characteristics of exposure, and specific job titles associated with an increased risk of glomerular disease.

We thank Miss Antonella Albenzio for her assistance with reviewing questionnaires and calculating exposure scores.

Requests for reprints to: Dr Porro Antonio, Istituto di Medicina del Lavoro, Universita' degli Studi di Bari, Policlinico, Piazza Giulio Cesare, 70124 Bari, Italy.

1 Churchill DN, Fine A, Gault MH. Association between hydrocarbon exposure and glomerulonephritis. An appraisal of the evidence. Nephron 1983;33:169-72.
2 Ravnskov U. Possible mechanism of hydrocarbon-associated glomerulonephritis. Clin Nephrol 1985;23:294-8.

3 Lauwerys R, Bernard A, Viau C, Buchet JP. Kidney disorders and hematotoxicity from organic solvent exposure. Scand J Work Environ Health 1985;11(suppl 1):83-90.

4 Nelson NA, Robins TG, Port FK. Solvent nephrotoxicity in humans and experimental animals. Am J Nephrol 1990;10: 10-20.

5 Roy AT, Brautbar N, Lee DBN. Hydrocarbons and renal failure. Nephron 1991;58:385-92.

6 Ravnskov U, Forsberg B, Skerfving S. Glomerulonephritis and exposure to organic solvents: A case-control study. Acta Medica Scandinavica 1979;205:575-9.

7 Ravnskov U, Lundström S, Nordén $\AA$. Hydrocarbon exposure and glomerulonephritis: evidence from patients' occupations. Lancet 1983;ii:1214-6.

8 Bell GM, Gordon ACH, Lee P, et al. Proliferative glomerulonephritis and exposure to organic solvents. Nephron 1985; 40:161-5.

9 Steenland NK, Thun MJ, Ferguson CW, Port FK. Occupational and other exposures associated with male endstage renal disease: A case/control study. Am J Public Health 1990;80:153-7.

10 Ravnskov U. Influence of hydrocarbon exposure on the course of glomerulonephritis. Nephron 1986;42:156-60.

11 Associazione Nazionale Emodializzati. Censimento dei servizi di dialisi e trapianto italiani al 31 dicembre 1989. Milano: ANED, 1990.

12 Fassbinder W, Brunner FP, Brynger $\mathrm{H}$, et al. Combined report on regular dialysis and transplantation in Europe, XX, 1989. Nephrology Dialysis Transplantation 1991;6(suppl 1):5-36.

13 Miettinen OS. Estimation of relative risk from individually matched series. Biometrics 1970;26:75-86.

14 Breslow NE, Day NE, eds. Statistical methods in cancer research. Vol 1. The analysis of case-control studies. Lyon, France: International Agency for Research on Cancer, 1980. (IARC sci publ No 32).

15 Mantel N. Chi-square tests with one degree of freedom; extensions of the Mantel-Haenszel procedure. Journal of the American Statistical Association 1963;58:690-700.

16 Van der Laan G. Chronic glomerulonephritis and organic solvents: A case-control study. Int Arch Occup Environ Health 1980;47:1-8

17 Harrington JM, Whitby H, Gray CN, Reid FJ, Caw T, Waterhouse JA. Renal disease and occupational exposure to organic solvents: a case referent approach. $\mathrm{Br} J$ Ind $\mathrm{Med}$ 1989;46:643-50.

18 Ravnskov U. Glomerulonephritis, renal carcinoma, and solvent exposure: bias from choice of referents. $\mathrm{Br} J$ Ind Med 1990;47:791. (Letter.)

19 Coppo $R$. The pathogenetic potential of environmental antigens in IgA nephropathy. Am J Kidney Dis 1988;12:420-4.

20 Emancipator SN. Immunoregulatory factors in the pathogenesis of IgA nephropathy. Kidney Int 1990;38:1216-29.

Accepted 13 January 1992 